\title{
DEVELOPMENT OF SIMULATOR FOR HYDRAULIC EXCAVATOR
}

\author{
TaeHyeong LIM*, HongSeon LEE** and SoonYong YANG * \\ * School of Mechanical and Automotive Engineering, University of Ulsan \\ 29 Mugeo-dong, Nam-gu, Ulsan,259-2731 Korea \\ (E-mail: bulbaram@mail.ulsan.ac.kr) \\ ** Department of Construction Equipment, Hyundai Heavy Industry \\ 1 Jeonha-dong, Dong-gu, Ulsan, 230-8988 Korea
}

\begin{abstract}
Hydraulic excavators have been popular devices in construction field because of its multi-workings and economic efficiency. The mathematical models of excavators have many nonlinearities because of nonlinear opening characteristics and dead zone of main control valve, oil temperature variation, etc. The objective of this paper is to develop a simulator for hydraulic excavator using AMESim. Components and whole circuit are expressed graphically. Parameters and nonlinear characteristics are inputted in text style. The simulator can be used to forecast excavator behavior when new components, new mechanical attachments, hydraulic circuit changes, and new control algorithm are applied. The simulator could be a kind of development platform for various new excavators.
\end{abstract}

\section{KEY WORDS}

Excavator, AMESim, Attachment, Hydraulic circuit

\section{INTRODUCTION}

Hydraulic excavator have been popular device in construction field because of its multi-working and economic efficiency. The application of this complex device will be extended manufacture, agriculture, undersea etc.

But its operating need very difficult skill because operator has to operate joysticks and pedals consequently. So accuracy of work is influenced by operator's skill. But environment of work is poor and difficult skill bring about feeling fatigued fast. Autonomous excavator can be a kink of solution about previous problems and many researches have been achieved by many researchers. British Columbia university in Canada, Carnegie Mellon university in USA and Sydney university in Australia have field robot center and have made a special studies with excavator and many construction equipment makes have prototype or autonomous excavator in part.

The paper map in field robot with excavator made before in my laboratory show that $56 \%$ of papers focus in modeling of attachment (Boom, Arm, Bucket) using Lagrange Euler equation and applying control algorithms but hydraulic circuit and valves are modeled very simply. For example, main control valves having nonlinear open area characteristics are modeled in simple variable orifice and logic valves are omitted. In many paper, researchers use robust controller in order to overcome nonlinearities created by complex open area characteristics and dead zone of valve, single acting cylinder, heavy weight of attachment. Because of many nonlinearities, experiments are positively necessary but limited by time, money, place etc.

The objective of this paper is to develop a simulator for 
hydraulic excavator using AMESim. Components and whole circuit are expressed graphically. Parameters and nonlinear characteristics are inputted in text style. The simulator can be used to forecast excavator behavior when new components, new mechanical attachments, hydraulic circuit changes, and new control algorithm are applied. The simulator could be a kind of development platform for various new excavators.

\section{ATTACHMENT MODEL}

Hydraulic excavator consist of upper frame, lower frame and attachment. Upper frame contain operating room, engine, pump, main control valve (MCV) and attachment is fixed to end of upper frame. Lower frame contain crawler or wheels and upper frame can rotate by swing motor. In this paper, attachment is modeled boom, arm, bucket except swing and drive and excavator model is 5 ton of Hyundai Heavy Industry.

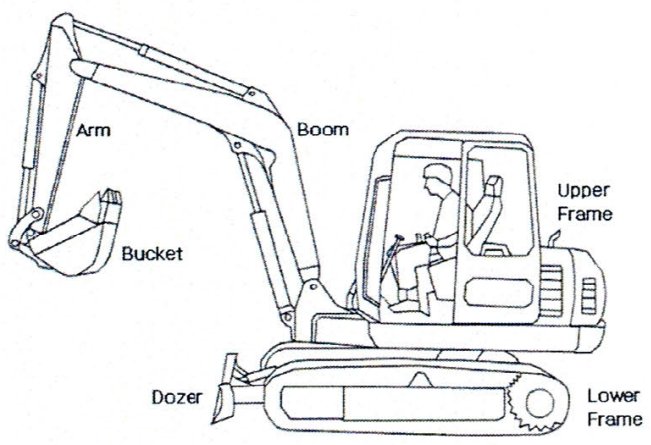

Figure 1 A Hydraulic Excavator

Fig. 2 shows the coordinate systems of excavator and motion equation was established by Lagrange equation.

$$
\sum_{j=1}^{n} H_{i j} \ddot{q}_{j}+\sum_{j=1}^{n} \sum_{k=1}^{n} h_{i j k} \dot{q}_{j} \dot{q}_{k}+G_{i}=Q_{i}, i=1, \ldots, n
$$

$H_{i j} \ddot{q}_{j}$ is inertia torque including interaction torque by off diagonal element of attachment inertia tensors, $h_{i j k} \dot{q}_{j} \dot{q}_{k}$ is Coriolis and centrifugal effects and $G_{i}$ is gravity torque.

Fig. 3 present AMESim model of attachment. The supercomponent of attachment is shown right and upper part in fig. 3 and this contain the rest components. Each component contain link's characteristic-length, mass, inertia etc.

The coordinates in fig. 2 are contained the attachment super- component. The inputs of supercomponent are force of cylinder and outputs are angular displacement of boom, arm and bucket.

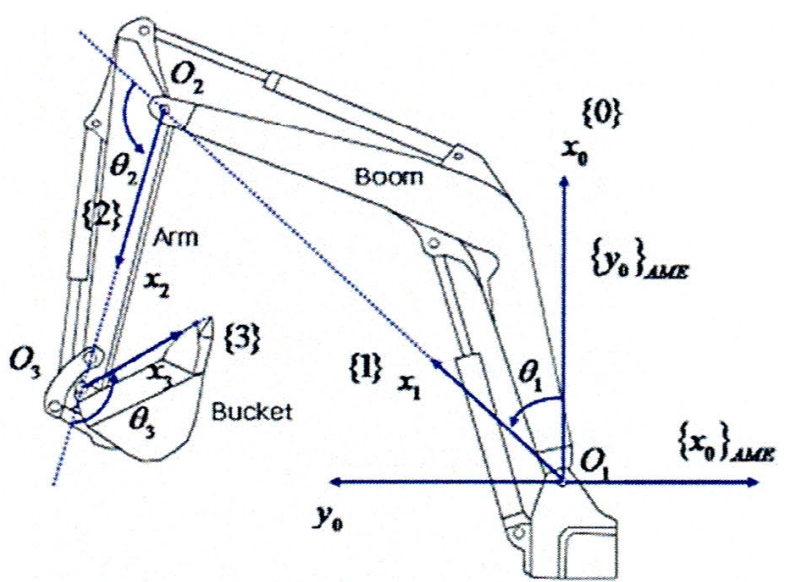

Figure 2 Coordinates system

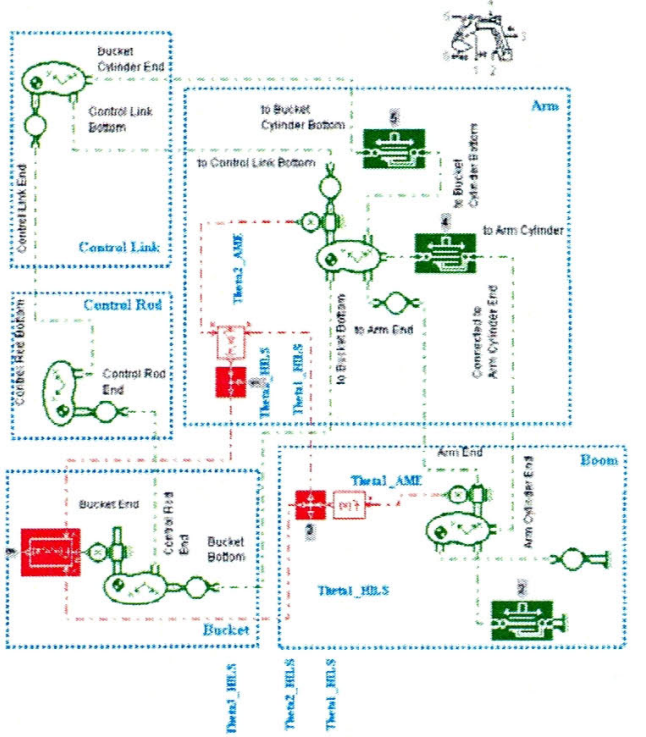

Figure 3 AMESim model of attachment

\section{HYDRAULIC CIRCUIT MODEL}

Main pump operated by engine make two type of pressures that main pressure work each cylinder and pilot pressure work spool of main control valve by operating joystick. If operator handle joystick or lever, pilot pressure push the spool of $\mathrm{MCV}$, the rate and direction of flow is decided by spool displacement and direction and flow rate can decide of direction and velocity of cylinder. Working area is assumed $2 \mathrm{D}$ in this paper, hydraulic circuit can be simplified like fig. 4 . Because boom up and arm dump need much flow rate, join of flow rate between boom 1 valve and boom 2 valve, arm 1 valve and arm 2 valve.

- Joystick

The role of joystick is supplying pilot pressure to MCV by operate angle. The AMESim model of joystick is shown in fig. 5. components in dotted square are contained supercomponent in left hand side. Operating of joystick is assumed to signal between -1 to 1 and 
pilot pressure to A, B port is directly proportional to signal. The input signal to joystick model is fig. 6 (a) and pilot pressure at port A, B is (b). In fig., pilot pressure response is proportional and delay is rare.

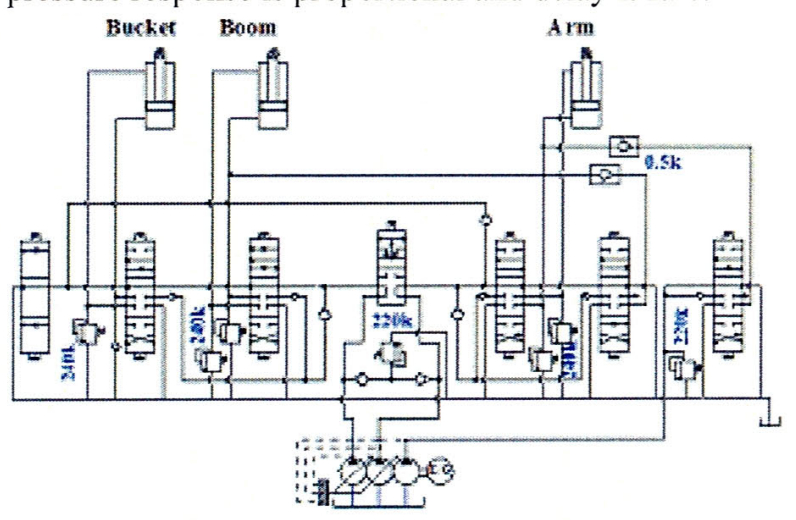

Figure 4 Hydraulic circuit of excavator

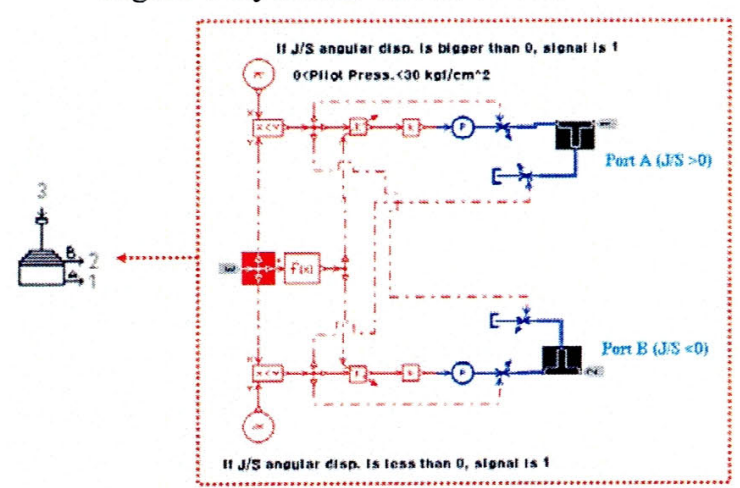

Figure 5 AMESim model of joystick

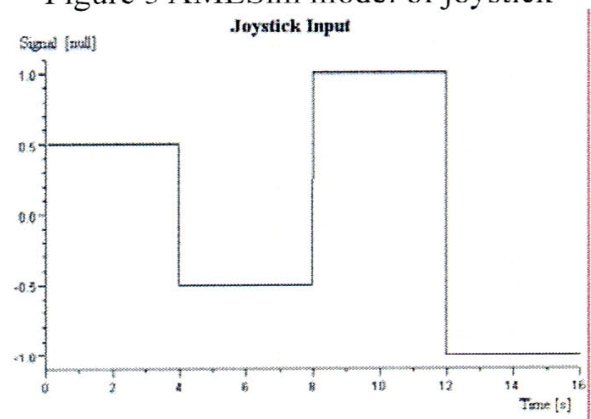

(a) Input signal

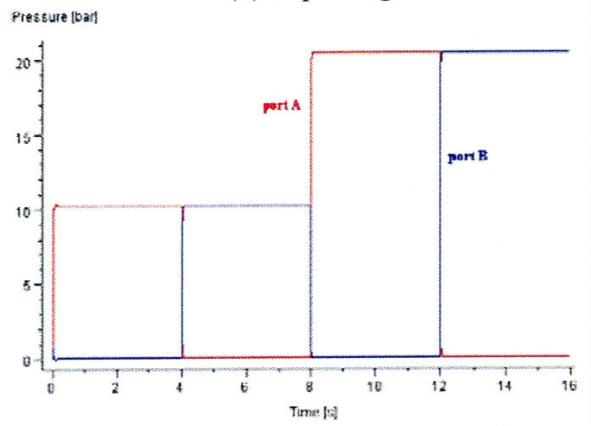

(b) Pilot pressure at A, B port

Fig. 6 Result of joystick model
- pump

The pump assembly consist of 2 variable pump for main pressure and 1 fixed pump for pilot pressure. Variable pump has control algorithm for energy saving, this can be cha- racterized to $\mathrm{P}-\mathrm{Q}$ diagram. The AMESim model of pump assembly is shown in fig. 7 . Various $\mathrm{P}-\mathrm{Q}$ diagram can be tested in this model easily because $\mathrm{P}-\mathrm{Q}$ diagram is inserted by text file. For verification of pump model, input and output $\mathrm{P}-\mathrm{Q}$ characteristics are shown in fig. 8. The solid line is input and dotted line is output. This pump model is verified with valve and cylinder.

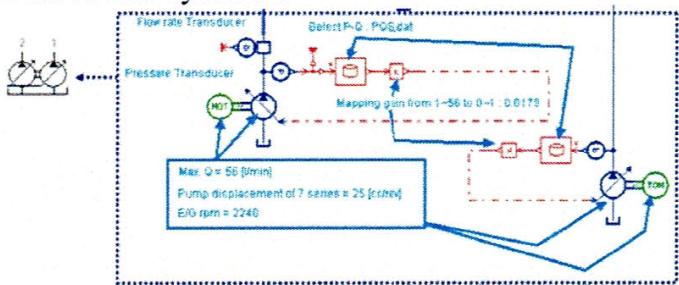

Figure 7 AMESim model of Boom 1 valve

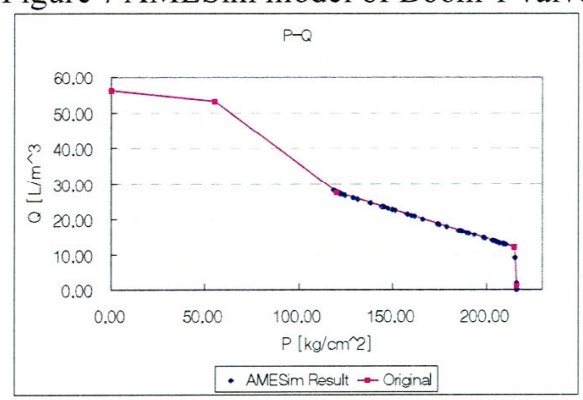

Figure 8 Result of pump model

\section{- Boom 1 valve}

Boom 1 valve, decide direction and velocity of boom cylinder mainly, is modeled 6 port 3 position valve. The spool displacement-Open area diagrams contain many nonlinearities dead zone, saturation and unproportional characteristic. These nonlinear diagrams are put into model text file. Fig. 9 show open area diagrams. The velocity of boom cylinder at up and down will be different because of nonsymmetrical diagram. Fig. 10 is AMESim model of boom 1 valve. The components in dotted square are packed into super- component in left hand side in fig. Fig. 11 show that spool displacement in various spring stiffness.

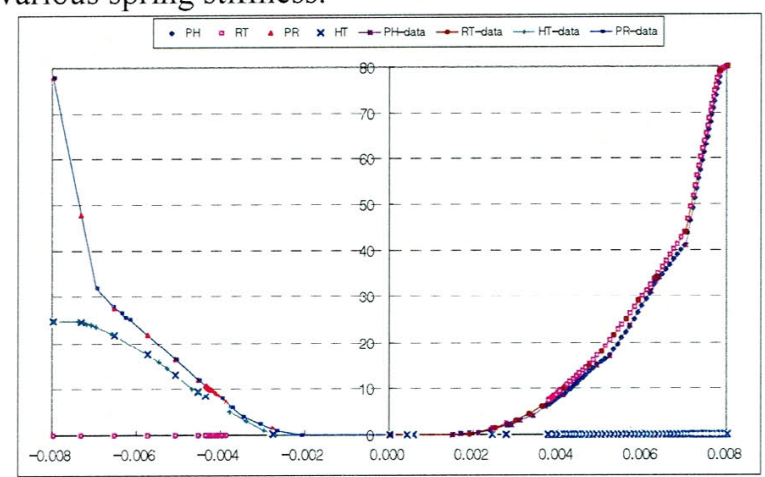

Figure 9 Open area diagram of boom 1 valve 


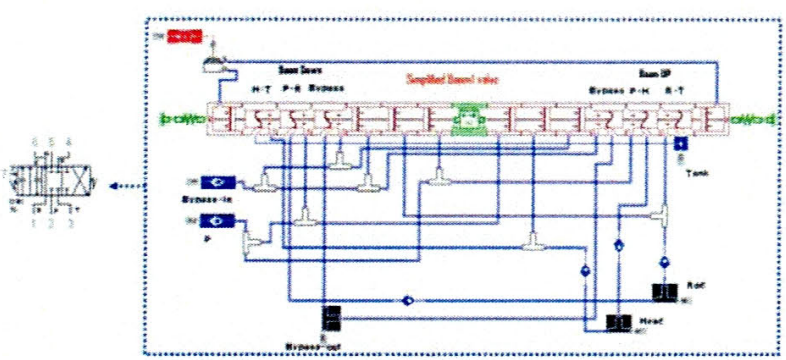

Figure 10 AMESim model of Boom 1 valve

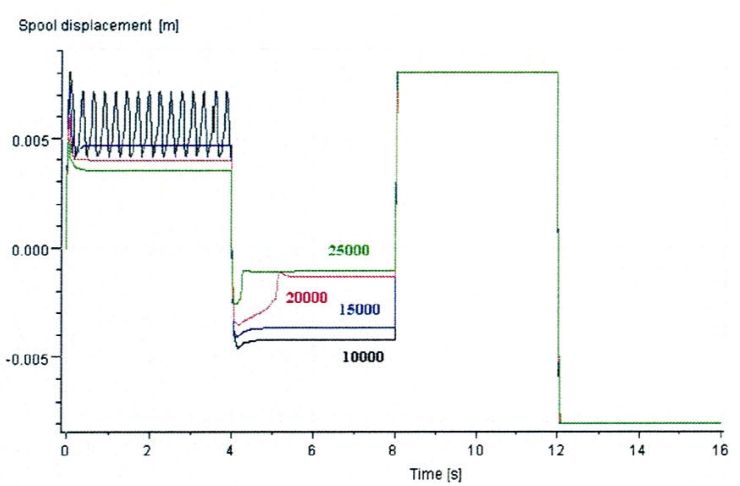

Figure 11 Spool displacement in variable stiffness

Stiffness variation has influence upon valve displacement. Too low stiffness produce oscillation of spool and errors between up and down are different to each other. 17000 make the error to minimum and spool displacement is shown in fig. 12. The displacement error at boom up is $0.316[\mathrm{~mm}]$, at boom down is $0.61[\mathrm{~mm}]$.

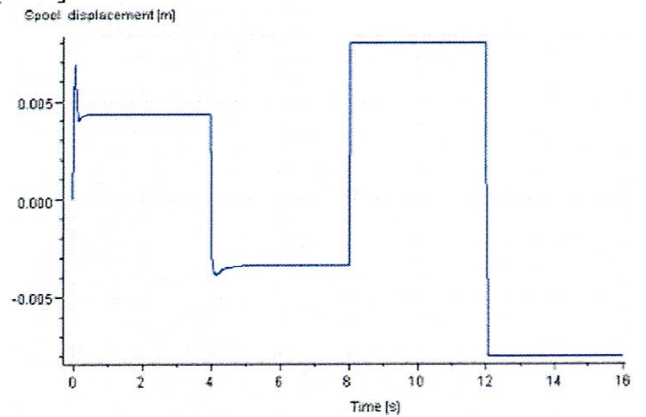

Figure 12 Spool displacement at stiffness 17000

\section{- Boom 2 valve}

The role of boom 2 valve is supply flow rate to boom cylinder at boom up. The boom 2 valve model has same structure with boom 1 valve model and different open area diagram. 20000 make the error to minimum and spool displacement is shown in fig. 13. The displacement error at boom up is $1.02[\mathrm{~mm}]$.

- Arm 1 valve

Arm 1 valve, decide direction and velocity of Arm cylinder mainly, has same structure with boom 1 valve model and different open area diagram. 20000 make the error to minimum. The displacement error at arm dump is $0.0534[\mathrm{~mm}]$, at arm crowd is $0.284[\mathrm{~mm}]$.
- Bucket valve

The final spring stiffness of bucket valve is 26000 and error at bucket dump is $0.042[\mathrm{~mm}]$, at bucket crowd is $3.17[\mathrm{~mm}]$.

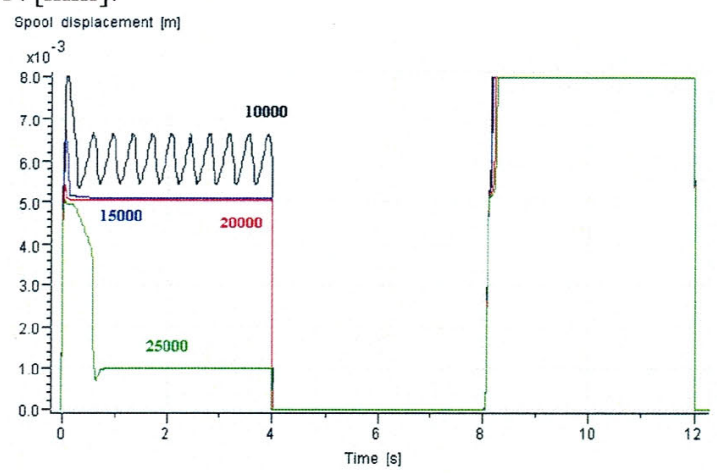

Figure 13 Spool displacement in variable stiffness

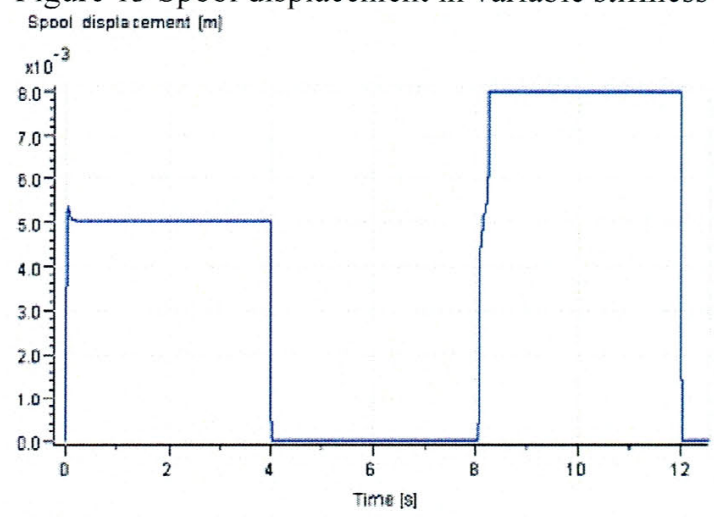

Figure 14 Spool displacement at stiffness 20000

- Main Control Valve(MCV)

The main control valve block consist of previous hydraulic components(3.1 3.6) is shown in fig. 15 . The working fluid through by pass go to tank and feature of circuit is similar to simpliflied circuit in fig. 4 . The port relief is added to cylinder in, out port.

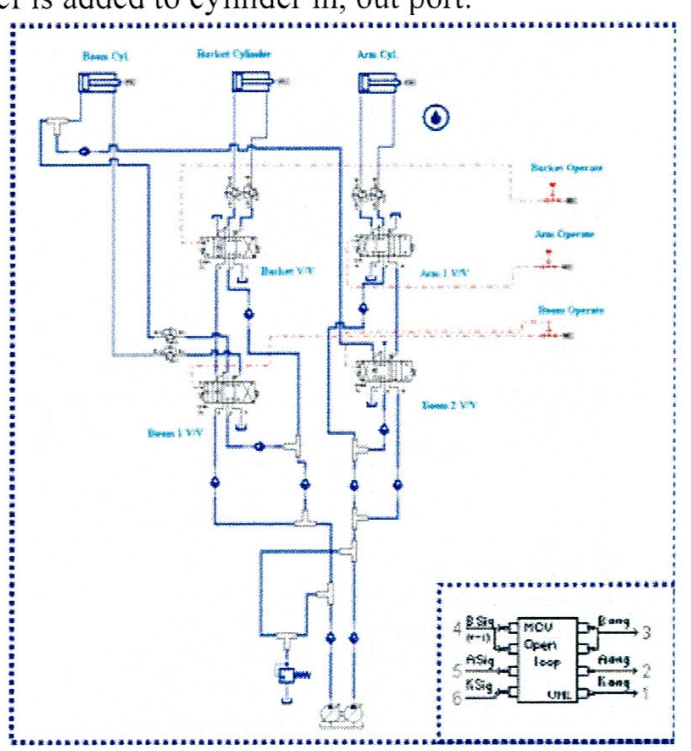

Figure 15 AMESim model of MCV 


\section{TOTAL MODEL AND SIMULATION}

Total excavator model is constructed in fig. 16 using previous models.

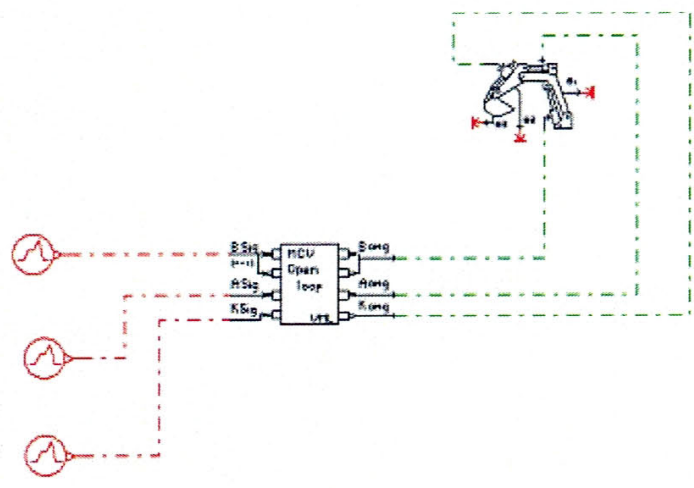

Figure 16 AMESim model of excavator

Though stiffness tuning was done, results at complex motion is different from it at single motion. Simulation condition is that operate joystick 50 [\%] to + for 4 [sec] , $50[\%]$ to,$- 100[\%]$ to + and $100[\%]$ to - of boom, arm and bucket simultaneously. Fig. 17 show spool displacement of boom 1 valve and boom 2 valve under simulation condition. Displacement error is bigger than simple motion that is because pressure at cylinder effect to MCV. Fig. 18 show angular displacement of attachment and pressures at boom cylinder are shown in fig. 19.

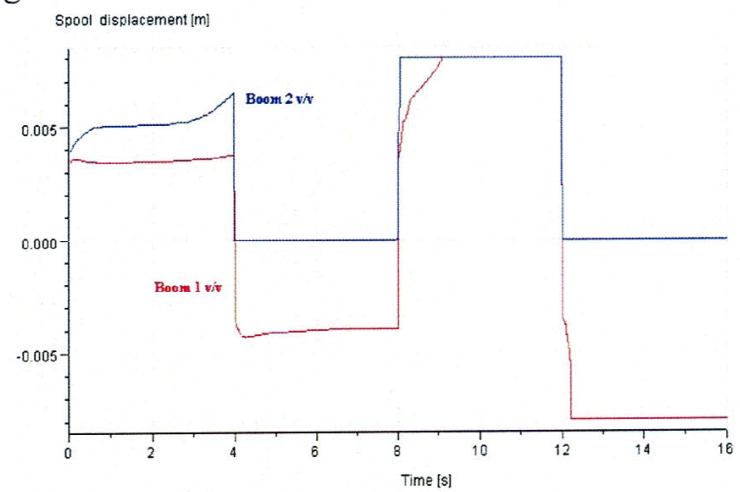

Figure 17 Spool displacement of boom valves at complex work

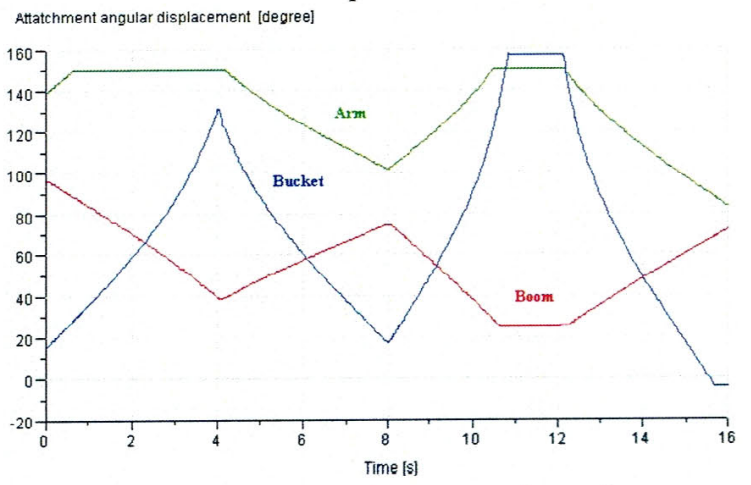

Figure 18 Angular displacement of attachments

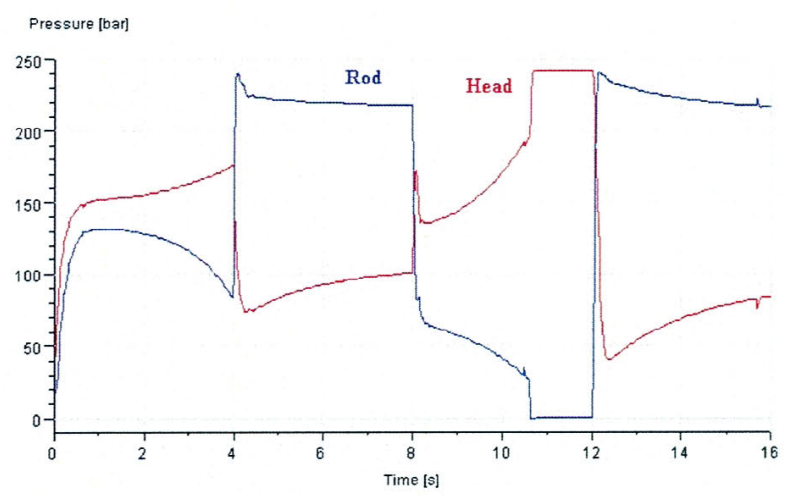

Figure 19 Pressures of boom cylinder

\section{CONCLUSION AND FUTURE WORK}

Each component of attachment and hydraulic circuit of excavator and total excavator is modeled with AMESim. To find constant spring stiffness make error to minimize tuning has done each valve model and result is as follow.

For boom 1 valve error at boom up is $0.316[\mathrm{~mm}]$, boom down is $0.61[\mathrm{~mm}]$ with stiffness 17000 . In case of boom 2 valve, error at boom up is $1.02[\mathrm{~mm}]$ with stiffness 20000. Arm 1 valve, error at arm dump is 0.0534 , arm crowd is 0.284 [mm] with stiffness 20000 . In bucket valve, error at bucket dump is $0.042[\mathrm{~mm}]$, at bucket crowd is $3.17[\mathrm{~mm}]$ with stiffness 26000 . So, constant spring stiffness can't satisfy accuracy of spool displacement for all condition. In order to proportional to displacement of MCV it is need to construct closed loop type MCV.

The AMESim model for total excavator will be used to verify new control algorithm or new component. Under being many limit to make an experiment with real excavator, this AMESim model will play an active part in simulator or test bench.

\section{ACKNOWLEDGMENTS}

This work was supported by the Korea Science and Engineering Foundation (KOSEF) through the research center for machine parts and material processing at University of Ulsan and Hyundai Heavy Industry.

\section{REFERENCES}

1. T. R. Kane, "Dynamics : Theory and Applications", McGraw-Hill, 1985.

2. R. P. Paul, "Robot manipultors : Mathematics, Programming, and Control", The MIT Press, 1981.

3. J. Watton, "Fluid Power Systems, Prentice Hall, 1989.

4. "AMESim User's Manual”, IMAGINE, 2000.

5. S. Y. Yang etc. "A Study on Trajectory Tracking Control of Field Robot", ICASE, Vo18, No.9, 2002. 